\title{
Descartes y la Constitución del Sujeto Moderno: Aportes de M. Foucault para el análisis de las tensiones entre el sujeto ético y epistemológico
}

En la primera conferencia dictada por Michael Foucault en 1973 en la Universidad Católica de Río de Janeiro, titulada La Verdad y Las Formas Jurídicas; el filósofo francés meditaba sobre el papel de la filosofía cartesiana en la constitución del sujeto moderno. Señalaba Foucault (1980) que

Hace dos o tres siglos la filosofía occidental postulaba, explícita o implícitamente, al sujeto como fundamento, como núcleo central de todo conocimiento, como aquello en que no solo se revelaba la libertad, sino que podía hacer eclosión la verdad.

Y agregaba, 
Sería interesante que intentáramos ver cómo se produce, a través de la historia, la constitución de un sujeto que no está dado definitivamente, que no es aquello a partir de lo cual la verdad se da en la historia, sino de un sujeto que se constituyó en el interior mismo de esta y que, a cada instante, es fundado y vuelto a fundar por ella.

Una perspectiva tal, la que de acuerdo al autor debiera comprender el análisis de las relaciones de poder en que se conforman ciertos tipos de verdad y no otros, así como ciertos modos de subjetivación en desmedro de otras formas posibles de constitución del sujeto; implicaría hacer una crítica radical del sujeto o lo que es lo mismo un análisis político de la genealogía del poder, y aún más, de la moral.

Pero, ¿qué sabemos de las prácticas sociales dominantes en la época en que se constituye y desarrolla el pensamiento de Descartes? De acuerdo a Foucault, este y no otro debiera ser el camino a seguir para construir la crítica radical e histórica del sujeto. Con las limitantes que a todas luces se encuentran en la lógica profundamente racionalista e individualista del Discurso del Método (1983), es difícil decir mucho al respecto.

Interpretamos del Discurso que al momento en que Descartes desarrolla su obra, existen cuando menos dos dominios sociales seguramente importantes en la constitución del sujeto: Por un lado la enseñanza escolástica fundada en el valor de la tradición y la herencia del conocimiento acumulado por la humanidad. En el colegio de La Fleche, Descartes entra desde muy temprano en contacto con esta tradición, de la cual más tarde decide apartarse para por sus propios medios la experiencia vivida y la soledad de su pensamiento con auxilio del método cartesiano o duda metódica), porque todo lo que pueden aportarle sus antiguos 
maestros, le parece relativo y en no pocas ocasiones irracional (por la ausencia de un método).

De otro lado, el absolutismo de la fe que como la escolástica antecede en el curso de la historia a la modernidad, y de alguna forma adquiere nuevos significados con ella; constituye otra dimensión social importante en la constitución del sujeto moderno. En este sentido el Discurso es bastante más claro, especialmente en el capítulo III dedicado a la moral provisional. En él, dice Descartes, uno de los principios y prácticas elementales que deben orientar el comportamiento es el control y dominio de los afectos, al punto de tratar de vencerse uno a sí mismo, cambiando sus deseos antes que el orden del mundo.

Desde la relectura que sobre la constitución del sujeto y la emergencia de los dominios de verdad y los saberes especializados realiza Foucault, el 'retiro' cartesiano o eso que parece una decidida renuncia a cualquiera enfoque historicista del sujeto y la verdad; puede ser analizado críticamente como parte de lo que el autor llama la emergencia histórica de ciertas tecnologías.

Recordemos que para Foucault el sujeto de conocimiento y el sujeto ético, la verdad y la moral tienen ellas mismas una historia. Por el contrario, seguir la lógica profundamente racionalista e individualista de Descartes, nos conduce irrevocablemente a admitir en la nacuraleza cierta línea de continuidad con la verdad y la moral.

Tres grandes tipos de tecnologías son responsables, dice Foucault, de las distintas formas de subjetivación de los seres humanos en la cultura occidental, y a cada una de ellas dedica el autor su análisis en campos más o menos específicos: una ontología histórica del ser humano en relación a la verdad que lo constituye como sujeto de conocimiento, una ontología histórica del ser humano en las relaciones de poder que lo constituyen y que constituyen a los 
otros sobre los que se actúa, y finalmente, una ontología histórica del ser humano en la relación ética por medio de la cual nos constituimos como sujetos de acción moral (Foucault, 1990).

La primera ontología hace referencia a las formas y procedimientos que asumieron ciertos campos del saber propios de las ciencias humanas, para al calor del Renacimiento y con la confianza puesta en el fiscalismo, acceder al estatuto de ciencia. Descartes no está ajeno a esta empresa científica. Sin embargo, su apuesta es contraria al empirismo gobernante en la época. Descartes se vuelca al interior de sí mismo y desde ahí constituye a un sujeto moderno epistémico, racionalista, individual. Para lograrlo se convierte a sí mismo en sujeto y objeto de investigación. Al fundir sujeto y objeto se produce la citada subjetivación del sujeto epistémico, cuyo norte lo constituye la búsqueda de la verdad.

La segunda ontología describe el campo de las prácticas sociales que hicieron posible escindir y controlar al sujeto. Se trata de las prácticas escindientes por medio de las cuales el sujeto es dividido en el interior de sí mismo o dividido de los otros, haciendo de él o de los otros, un objeto a dominar. En el Discurso, la partición más clara del sujeto es la que se realiza entre el ser humano racional y el ser humano irracional. Descartes concede al primero el dominio de un método racional para acceder a la verdad y escapar al mundo de las apariencias. Asimismo, concede a este sujeto el acceso a la libertad y el dominio de las fuerzas psicológicas, sociales y naturales. El sujeto irracional por el contrario está condenado a vivir en una especie de infancia perpetua, susceptible de influenciar por dominios sociales como la tradición escolástica, y (no estamos seguros de si es intención de Descartes denunciar esto) el absolutismo de la fe. 
La tercera ontología se refiere al modo en que el ser humano ha aprendido a reconocerse como sujeto de una sexualidad. Se trata de lo que Foucault llama las tecnologías del yo.

Se trata, nos dice, de 'estudiar la constitución del sujeto como objeto para sí mismo: la formación de procedimientos por los que el sujeto es inducido a observarse a sí mismo, analizarse, descifrarse, reconocerse como un dominio de saber posible. Se trata, en suma, de la historia de la 'subjetividad', si entendemos esta palabra como el modo en que el sujeto hace la experiencia de sí mismo en un juego de verdad en el que está en relación consigo mismo (Foucault, 1990, p. 21).

Aunque sabemos que el sujeto moderno cartesiano se define más como sujeto epistémico que como sujeto ético, porque lo importante es para Descartes alcanzar la verdad y no el bien, creemos que en la operación que obliga a Descartes a analizarse cuidadosamente y conducirse con estricto apego a un método de razonamiento, se intersecan o rozan el dominio de la ética y de la epistemología.

Para Descartes, se domina porque se conoce; dominar es pues la consecuencia lógica de un acto voluntario de la razón. Para Foucault, se conoce porque se quiere dominar; dominar es entonces la resultante no de cierta continuidad natural e innata, sino de los juegos de verdad que se construyen a través de los discursos o lo que es lo mismo, el conjunto de juegos estratégicos y polémicos, de relaciones de fuerza, de dominación y resistencia, que forman parte de las prácticas sociales.

Para Descartes el conocimiento se encuentra, se construye solo como método porque la legalidad que rige la naturaleza es previa al ser humano y el ser humano no la puede alterar. Hay pues cierto determinismo en el pensamiento de Descartes. Este determinismo refleja, nos parece, la vena 
conservadora y tradicional de la filosofía cartesiana, su apego a la moderna filosofía del progreso y a la confianza que sobre las ideas innatas depositan el mundo antiguo y el medieval.

Siguiendo a Foucault, aquí se sostiene que a lo interno de las maniobras con las que Descartes construye al sujeto moderno (la quiebra de la tradición, pasar de un sujeto ético a uno epistémico), habría que rastrear las prácticas sociales, los juegos de verdad y las relaciones de fuerza que hicieron posible formar a este y no a otro sujeto moderno (entendido como sujeto epistémico y como sujeto ético).

A nuestro parecer, el riesgo de seguir el mismo procedimiento racionalista de Descartes para analizar su obra, es grande. Descartes nos habla de la constitución del sujeto moderno epistémico, pero re-huye a hablar de él mismo como sujeto ético que escribe desde un lugar. Aún más, parece considerar que la conducta individual no epistémica (lo mismo que la teología y el sistema socio político), escapa a las posibilidades del racionalismo. Pero según parece, no por eso deja de tener conciencia de que el conocimiento se construye desde un lugar, una biografía y una historia social (piénsese por ejemplo en sus reflexiones sobre los escolásticos y los límites y peligros del relativismo cultural).

¿Acaso no refleja esto los juegos de verdad, múltiples, contradictorios; las relaciones de fuerza, de dominación y resistencia que se configuran en las prácticas sociales desde donde en un lugar y no en otro (como europeo, hombre blanco, católico, intelectual) vive y desarrolla su obra Descartes? ¿Acaso no refleja esto la tensión entre cierto objetivismo epistemológico y cierto subjetivismo ético que se intersecan en la duda metódica de Descartes? ¿Puede ser vista la duda metódica además que como un procedimiento racional para acceder a la verdad y a la libertad (de la naturaleza, de las dependencias del cuerpo, de los sistemas políti$\cos$ ), como una técnica de vigilancia o lo que es lo mismo 
una suerte de tecnología del yo, a partir de la cual se conoce al sujeto para dominarlo?

Si lo propio de la modernidad es como dice Foucault el abandono de la segunda parte de la máxima deifica propia del mundo antiguo, que rezaba así: Conócete a ti mismo y ocúpate de ti mismo; esto se debe a que por un lado ocuparse de sí mismo contraría al absolutismo de la fe y al ascetismo cristiano palpables en la vigilancia y el castigo dictados por las prácticas sociales de la Santa Inquisición.

Por otra parte, es producto de la preeminencia que para entonces tomaba el sujeto epistemológico, en buena medida fundado a partir del sistema filosófico construido por Descartes. Y, finalmente, dice Foucault, existe una tercera razón para explicar el abandono del ocúpate de ti mismo deifico, y en esto como en los dos motivos anteriores Descartes tiene una cuota importante de responsabilidad. Se trata de la fundación misma de las ciencias humanas y de lo humano como sujeto cognoscible, posible de conocer porque él, el que conoce, lo que conoce (nuevamente él mismo) y el método para conocer, pueden ser todos racionales, no susceptibles a cualidades que como la verosimilitud opacan el conocimiento de la verdad última de las cosas.

El sujeto como objeto que se conoce a sí mismo, sería entonces un objeto enteramente dado que es preciso conocer. Suponerlo dado, constituido, nos podría conducir al error de pensar que la subjetivación del sujeto moderno que hace posible Descartes, es pues solamente epistemológica y no ética (o política).

En resumen, El Discurso del Método es un texto susceptible de analizar con un enfoque crítico e histórico. Acá no se han querido sino trazar muy modestamente, una serie de interrogantes que podrían profundizarse ${ }^{1}$ para comprender

\footnotetext{
'Deberian de revisarse por ejemplo El Tratado de las Pasiones de Descartes, e Historia de la Sexualidad de M. Foucault. En la primera conferencia de Toronto, Foucault analiza particularmente el papel de la filosofia cartesiana en la constitución del sujeto moderno.
} 
mejor lo que hemos llamado las tensiones entre el sujeto ético y epistemológico cartesianos.

\section{Referencias Bibliográficas}

Descartes, R. El Discurso del Método. EDUCA, San José, costa Rica, 1983.

Foucault, M. La verdad y las formas jurídicas. Editorial Gedisa, Barcelona, España, 1980.

Foucault, M. Tecnologías del Yo. Ediciones Paidós, Barcelona, España, 1990. 